\section{El cadáver humano en el arte y la bioética: la Pietà Rondanini de Miguel Ángel}

\author{
GUSTAVO FIGUEROA
}

\section{The human corpse in arts and bioethics: Michelangelo's Pietà Rondanini}

According to bioethics, life is a fundamental but not an absolute good. Therefore the value of a person resides in being alive, no matter in which state such person is. The concept of brain death is legally and ethically accepted as the definition of death. In artworks, human beings are revealed as they are. Michelangelo's Pietà Rondanini captures and captures what a human corpse is, in its most intimate appearance. The artist boldly reveals its essence.

(Rev Med Chile 2016; 144: 241-246)

Key words: Bioethics; Brain Death; Corpse; Euthanasia; Medicine in Art.
Departamento de Psiquiatría, Escuela de Medicina, Universidad de Valparaíso

Recibido el 22 de julio de 2015 , aceptado el 16 de noviembre de 2015.

Correspondencia a: Dr. Gustavo Figueroa C. Departamento de Psiquiatría, Escuela de Medicina Universidad de Valparaíso, Valparaíso, Chile. gfigueroacave@gmail.com
$\mathrm{E}$ 1 cadáver humano ha ocupado un puesto singular desde la época prehistórica de la humanidad, como lo atestiguan cánticos, ritos y ceremoniales en distintas culturas ${ }^{1}$. La medicina occidental lo ha estudiado desde que se convirtió en tekhné iatriké -ciencia médica- y actualmente constituye objeto de análisis, investigación y experimentación ${ }^{2-4}$. Los hallazgos de las revolucionarias biotecnologías impulsaron a la bioética a impugnar la conceptualización tradicional del morir y, como consecuencia, a cuestionarse sobre cuándo se está vivo, muerto o se es cadáver, obligando a replantearse su naturaleza desde nuevos fundamentos ${ }^{5-7}$.

En el arte, ha alcanzado un lugar preponderante desde las pinturas en las cavernas. Movido por intereses artísticos, religiosos y metafísicos, Miguel Ángel abrió horizontes novedosos y perspectivas insospechadas referidos al cadáver humano en cuanto éste es expresión corporal del espíritu en su momento final, espíritu que siempre es trascendente al mundo ${ }^{8-10}$. Aunque trabajado en diversas obras, es en la Pietà Rondanini donde indagó el sentido último del cadáver ${ }^{11-13}$.

Este trabajo tiene como meta investigar cómo el arte y la bioética develan al cadáver como fin inherente a nuestra condición humana. Primeramente, se mostrará cómo entiende la bioética la situación del cadáver. A continuación, se analizará lo que la Pietà Rondanini agrega a este enfoque, y, finalmente, se sacarán implicaciones a partir de los hallazgos bioéticos y artísticos.

\section{Ser cadáver}

La muerte es una estructura esencial del ser humano y así lo señaló Heidegger al mostrar su carácter ontológico: ser-referido-a-la-muerte (Sein-zum-Tode) $^{14,15}$. Por tanto, en el hombre el morir no es un acontecimiento que lo asalta desde el exterior, sino es un modo-de-ser que, por pertenecer a su esencia, posee complejidades más allá de un dejar-de-vivir (ableben). Es su posibilidad "más propia", "absoluta", "insuperable", "cierta" e "indeterminada"16; aún más, como posibilidad puede ser auténtica o inauténtica (uneigentilich). Fundamentada en esta ontología, está la perspectiva óntica: existe el morir biológico, que evidencia nuestra pertenencia a la naturaleza; semejante al resto de los seres vivientes, irrumpe como terminar (verenden) generando la descomposición orgánica 
que, desde ese instante, constituye el cadáver. Pero además el morir es un hecho cultural, esto significa histórico, porque, en lugar de estar en la historia, el hombre "es" histórico (zeitlich) ${ }^{17-19}$. Es en la historia donde ha exhibido profundas diferencias en las diversas civilizaciones, relegando lo biológico a ser sólo una parte del proceso ${ }^{20,21}$. Así Ariès distinguió cuatro maneras de morir en Occidente-amaestrada, propia, ajena y prohibida ${ }^{22,23}$.

Partiendo de la medicina, Gracia recordó que la eutanasia es, etimológicamente, bien morir o morir según la perfección porque, para Platón y Aristóteles, la finalidad de la existencia -la eudaimonía o felicidad- es vivir y actuar acatando el bien $(e \hat{u})^{24}$. Desde Grecia, el morir se desarrolló en tres etapas: ritualizado, medicalizado y autonomizado. En la primera, el rito garantiza el paso de un estado a otro; en la segunda, el médico se encarga de conducir a buen término la finalidad de la vida puesto que su conocimiento sanciona lo óptimo; en la tercera, el salto se invierte porque ahora es el paciente el que decide su bien morir, más allá de tuiciones religiosas o profesionales. La bioética médica generó este viraje al subordinar el principio de beneficencia al de autonomía: el enfermo determina cuál es su destino final, más allá si doctores, familiares o sociedad no compartan su decisión ${ }^{25}$.

Los progresos biomédicos -especialmente, suspender todo tipo de terapia y donación de órganos- pusieron en cuestión no sólo el decidir, sino dos asuntos decisivos pero distintos ¿cuándo alguien objetivamente está muerto? y ¿cuándo se le considera cadáver? Clásicamente, se hablaba de "muerte natural" al producirse la cesación de las funciones del corazón y pulmón, concepción griega que postulaba que la muerte es pérdida del espíritu vital. El hombre es animal, aunque racional (zoon lógon ekhón $)^{26}$, por lo que el criterio de muerte se centró en lo cardiopulmonar, ya que el atributo de lo animal reside en el corazón. Este procedimiento no fue certero: puede ocurrir su cesación sin que el sujeto pierda el espíritu, pero ahora propio de la vida intelectiva, como en traumatismos cerebrales ${ }^{27}$.

Controversias surgidas de la medicina de urgencia $y$, específicamente, del estado vegetativo permanente, dieron originen a una nueva conceptualización, más allá de las dos muertes del espíritu-vital y del espíritu. Son pacientes con privación irreversible de su conciencia, aunque sin cesación de las funciones cardiopulmonares; están vivos aunque muertos corticalmente, por lo que jamás recuperarán su condición propiamente humana. Pero existe un nivel más primario que la muerte cortical: la muerte del sistema nervioso. Estas distinciones resolvieron dilemas sobre la donación de órganos y se habló de donación de vivo a vivo. La bioética entró en el debate y planteó sus reparos tanto en relación a la determinación del momento de la muerte como en la definición de cadáver. Lo que buscó fue respetar los principios de no-maleficencia y justicia que, aunque prima facie, constituyen los mínimos éticos de la medicina. Se optó por "muerte cerebral" y, en lugar de "donación de vivo", se prefirió "donación de cadáver”. Esta reconceptualización eliminó parte de las proclamas morales cómplices de eutanasia directa, considerando al cadáver un "bien social" antes que un "bien privado" para evitar vulnerar la autonomía del sujeto ${ }^{28,29}$.

Actualmente el cadáver comprende una triple dimensión: social-histórica, médica y bioética. La bioética ha acentuado que es una condición de la existencia humana y, como tal, se rige según el principio fundamental de Kant: respeto de todos los seres humanos porque tienen dignidad ${ }^{30}$. Pero este principio no es absoluto y a priori, tiene una estructura histórica y requiere, para ser aplicado, proceder con prudencia, sabiendo que nunca se alcanzará la certeza absoluta cuándo se está frente a un cadáver. Solamente al ingresar en la etapa que Virchow catalogó de muerte celular existe certeza total.

\section{La Pietà Rondanini}

El arte es un modo de conocer la realidad que, más allá de la belleza, intenta acceder a su esencia. Heidegger recalcó que, a diferencia de la ciencia (médica) que demanda certeza y validez mediante el imponer, calcular, someter, el arte trae-a-presencia lo latente, des-encubre lo velado, deja-ser (sein-lassen) al fenómeno mismo ${ }^{31-33}$.

Un tema atraviesa toda la obra de Miguel Ángel Buonarroti (1475-1564): el cuerpo humano ${ }^{34}$. Si Heidegger ha señalado que el Dasein humano es ser-en-el-mundo, Miguel Ángel hace suya esta caracterización, pero entendiéndola a partir de la corporalidad. No se trata de una oposición ni menos rectificación -especie de reproche anticipa- 
do por Miguel Ángel al hecho tan condenado que Heidegger describe un Dasein incorpóreo- ${ }^{35}$, sino de una comprensión diversa cuando se adopta la perspectiva del arte. Su fundamento: el cuerpo es la condición de posibilidad de la existencia del hombre, tanto del terrenal como del iluminado por la gracia "Hércules fundiéndose con Cristos", según Baudelaire ${ }^{36}$. También de lo divino, porque Dios y los ángeles igualmente se hacen presente como entes corpóreos: toda la creación y quien ha llevado a cabo la creación, pueden mostrase al hombre solamente cuando están insertos en un cuerpo. Pero se necesita saber interpretar y descifrar en estos cuerpos los signos de lo humano y de lo divino, y este instrumento de comprensión es el arte. Miguel Ángel des-vela la realidad a través del cuerpo humano.

El cuerpo posee una anatomía compacta que permite medir con exactitud su figura; apariencia estática, según la bosquejan Vesalio y Falopio en cadáveres ${ }^{4}$, o Durero en retratos-pero de un modo algo endeble, molto debole, según Miguel Ángel ${ }^{37}$. Lo débil radica en que no hay movimiento y para él la esencia del cuerpo humano es dinamismo, que se expone en actos y gestos. La belleza estatuaria propia de sus contemporáneos cede su lugar a la actividad vital como símbolo de lo humano, según vemos en el Esclavo que se despierta: es el nacimiento de la conciencia humana; desde el núcleo de la materia informe de mármol emerge el rostro del esclavo, pero que no se desprende del todo de esta masa compacta; se esbozan rasgos de su cara como en lucha violenta contra la pesadez del mármol por llegar a ser una criatura humana, aunque aún no consigue esa meta. Su técnica del non finito, del inacabado, le permite revelar esta indefinición. Si ésta simboliza la batalla por ingresar en lo humano desde lo inanimado, el morir será el combate por desprenderse de lo humano y alcanzar otro nivel de realidad.

La Pietà Rondanini será la última escultura que intentará cincelar hasta seis días antes de morir?. Trabajó en ella de manera inconstante desde 1550 (¿1556?), pero con pasión incontenible. Esto indica que fue una obra absolutamente personal, irrenunciable, intransferible, producto de su relación definitiva con su muerte y trascendencia: representa su concepción última de los alcances del arte para captar el final y la finalidad del hombre.

Tres Pietà la precedieron: San Pedro (14981500), Santa María del Fiore en Florencia (1547-
1555) y Palestrina en Florencia (probablemente esculpida por un discípulo bajo su supervisión). Tres perspectivas de la muerte y del destino del hombre cuando deviene cadáver que, aunque magistrales, dejaron insatisfecho al artista. Insatisfacción profundísima hacia la Pietà de Santa María del Fiore por dos motivos. Primero, destinada a su propia sepultura, exigía -y no cumplió- haberle infundido un intransferible sentido personal. Segundo, la figura de Cristo le resultó insuficiente, ya que mutiló su pierna y brazo izquierdos. En cualquier caso, no volvió a trabajarla sin dar mayor explicación. En las tres, Cristo muerto; en todas ellas ¿el cadáver de Cristo?

\section{El cadáver de Cristo}

$\mathrm{Su}$ enamoramiento espiritual hacia Vittoria Colonna produce un cambio de estilo: su inclinación por lo monumental muta hacia un estilo más espiritualizado. Sus discusiones neoplatónicas le posibilitan visualizar los variados sentidos que Platón atribuyó al cuerpo o sôma: tumba (sêma), cárcel (sêma) y signo (sema); el cuerpo es cuerpo-tumba o cuerpo-cárcel en el que el hombre está prisionero, aunque también es cuerpo-señal, que reclama ser interpretado ${ }^{38}$.

Con una postura antropológica que recuerda las indicaciones de Ortega y Gasset sobre la intimidad del hombre -vitalidad, alma y espíritu ${ }^{39}$, Laín Entralgo mostró que para Miguel Ángel el cuerpo tiene una triple dimensión: carnal, personal y espiritual ${ }^{40}$. El cuerpo carnal expresa la vitalidad inherente a la naturaleza. El cuerpo personal señala la triple condición de la persona -libertad, intimidad, apropiación- que se realiza en proyectos de vida. El cuerpo espiritual está más allá, trascendiendo hacia la meta suprema. Estas valiosas indicaciones necesitan ser complementadas en otra dirección: primero, cuerpo-muerto y, luego, cuerpo-cadáver. Es en Cristo donde Miguel Ângel enseña cómo irrumpe la muerte y se trasmuta en cadáver. La Pietà de Santa María del Fiore es el primer paso (muerte) y la Pietà Rondanini el segundo (cadáver) una especie de secuencia progresiva.

En la Pietà de Santa María del Fiore, Nicodemo -rostro de Miguel Ángel- asiste a María a sostener a Cristo y con su brazo en la espalda de ella, a modo de gesto de protección, reúne a la madre con el hijo. La Virgen, con el rostro transfigura- 
do, lo acoge con amor maternal, sirviéndole de último puntal, mientras María Magdalena mira hacia nosotros, señalándonos esperanzadamente nuestro futuro si entendemos -y seguimos- devotamente la enseñanza del acontecimiento que acaba de estremecer a la humanidad. Cristo está muerto. Su muerte indudable se patentiza en su cuerpo, doblado en dos sitios; ya inerte y exangüe, se desliza pesadamente hacia abajo. Este cuerpo posee una triple dimensión, señal que la muerte mutila en tres niveles. 1) Muerte vital. La solidez de su contextura, sus formas macizas comienzan a perder volumen a medida que descendemos hacia su pierna derecha; su resbalarse obedeciendo las leyes de la gravedad, denuncian que la vida se extinguió tras el martirio final. Sus fuertes brazos son signos de la ardiente vitalidad que lo mantuvo sin claudicar durante todo su suplicio, aunque su torsión desmañada delata que el intenso fuego que los hacía moverse se consumió. Arrasado con furia, su torso enseña las huellas de la pasión pero que, por haber acaecido hace algunas horas, todavía resiste con dignidad bajo el brazo de su madre que no se resigna a que se desfigure. Las emociones y anhelos que impulsaban las diferentes partes de su organismo están ausentes; sus manos se doblan inanimadas hacia la tierra, como si los hilos que las movían se hubieran cortado, incapaces de obedecer una orden interior. Su pie flácidamente abatido, yace sin esperanza de recuperar su posición erecta; 2) Muerte propia. Las facciones serenas de Cristo delatan que la misión ha llegado a su término, exhibiendo una paz interior. Su rostro, sin arrugas ni marchito, reposa sosegadamente en la cabeza de su madre tras el cometido más propio, empuñado con valentía sobrehumana aunque henchido de humildad. La muerte no lo ha sorprendido, no hay enervación, ni pasmo, ni contracciones previas al morir: la ha acogido como momento de realización de su vocación y destino enviado por su Padre. Su cuerpo fláccido no es sólo el que ha perdido su vitalidad, sino, sobre todo, el que descansa entregado en armonía a su creador, sin rabia ni rebeldía; 3 ) Muerte narrativa. El tiempo despliega su presente como presencia, cuerpo material deslizándose entre los mortales que le ayudan a que no se laceren sus restos humanos; presencia rotunda, compacta, se impone a todos, no se la puede eludir ni negar, no tolera que se olvide su solidez, densidad, peso. En este presente está inserto su pasado y su futuro. El pasado está referido por señales inequívocas hacia una historia dolorosa, pero sagrada: los castigos físicos soportados en pos de la misión del creador; en palabras de Heidegger ${ }^{14}$, es como si su cuerpo hablara: no fui un ser que fue ultimado, como si todo hubiera terminado, sino que "yo soy sido" aquel que sufrió por la humanidad, mi cuerpo "es sido" (Gewesenheit) este calvario, el "sido" está incluido en el "es", no hay olvido. El futuro no es sólo algo por venir, es el último "para qué" que muestra su rostro: la fusión con el Padre. Fusión que se inicia con la faz de su madre, faz sin terminar porque ya se está uniendo con su hijo hacia una conciliación final. Cristo está muerto pero es humano y lo humano se dirige hacia una finalidad última y trascendente, es un venir-hacia-sí-mismo (zu-sich-kommen).

La Pietà Rondanini muestra a Cristo, pero ahora no sólo muerto sino cadáver que, para Miguel Ángel, es el cuerpo de la revelación. La revelación es doble, del destino terrenal y del destino trascendente. La rudeza del rostro y el cuerpo casi esquelético de Cristo dan a entender que la carne está disolviéndose o desintegrándose: lo viviente no sólo ha terminado -muerto-, sino está macerándose. Poseedor de una delgadez extrema, con despojos de músculos y tejidos, apenas se sostiene sobre sus pies que cuelgan de las piernas, parece como que empieza a ascender hacia los cielos superando la ley de gravedad. La técnica del non finito alcanza su máxima expresión porque Cristo y María están des-humanizándose. La Virgen se propone sostenerlo con su brazo izquierdo, pero este brazo desconoce sus límites con el cuerpo de su hijo y se ignora si la madre trata de infundir calor al hijo o éste a ella. La cara de Cristo ha perdido sus facciones inferiores y las zonas superiores son sólo restos de las que alguna vez poseyó. ¿ $\mathrm{No}$ es máxima expresión de desintegración ese brazo derecho amputado de su cuerpo? 1) Fisiognomía del cadáver. La apariencia ante el otro está llena de patetismo en una atmósfera siniestra, pero también misteriosa, de un arcano que pide ser revelado; acercarse a su figura es exponerse ante algo ominoso y numinoso simultáneamente. Habla de lo terreno -oscuro e insondable- pero también de un camino ascendente que quiebra toda medida humana. No es pura tenebrosidad, tampoco pura iluminación; está lo cenegal, está lo ultraterrenal. Se apunta a la ultratumba, pero se invoca a lo celestial; 2) Lo existencial del cadáver. 
En cuanto cadáver - de la raíz latina cado, caerCristo está cadendo, cayendo, pero este no sostenerse en lo terrenal es una caída definitiva de esta vida, apuntando a un sostenerse verdadero que es en Dios. Heidegger ha señalado que el hombre es ek-sistencia: un estar-fuera-de-sí ${ }^{14}$. El cadáver de Cristo señala que él está cumpliendo su esencia: ya no está más en sí-mismo, su interioridad está volcada en lo otro completamente distinto de él, en su Padre; esto él lo sabía mientras deambulaba por el mundo, pero ahora comienza a experimentarlo. Está ingresando en el reino de Dios con una cuerpo transfigurado, que siempre es cuerpo, pero absolutamente diferente del mortal: cuerpo más allá de toda carnalidad. Ese nuevo modo de ser cuerpo Miguel Ángel no lo muestra; se limita a insinuarlo como cuerpo espiritual, el cuerpo iluminado por la gracia.

\section{El cadáver humano}

1) La bioética ha enseñado que el cuerpo del hombre merece consideración y respeto porque le es inherente una dignidad, aunque no tiene carácter absoluto. Para Miguel Ángel, el cuerpo es la condición de posibilidad de su ser y del ingreso al ser de la realidad última, por lo que posee una constitución especial tanto ontológica como teológica.

2) El principio de no-maleficencia impide ejecutar variadas intervenciones médicas, lo que obliga a modificar la noción de muerte en acorde a los avances científicos y situaciones sociales. El cadáver es aquel cuerpo que se ha des-humanizado, que ha perdido definitiva e irreversiblemente su condición de persona, aunque en ocasiones todavía puede estar vivo, por lo que tolera que se puedan llevar a cabo maniobras en él que suelen estar regularmente prohibidas.

3) La Pietà Rondanini enseña que el cadáver no sólo es des-integración, des-composición, conversión en polvo, sino que, incrustado en sus restos, hay signos que apuntan a la vida iluminada por la gracia, camino ascendente del espíritu aunque irrepresentable, porque Miguel Ángel no supo de ella, sólo la atisbó oscuramente.

4) El cuerpo del hombre es para la medicina de dominio perfecto: el individuo (dominio privado) o la sociedad (dominio público) son señores de él. Así también el cadáver. Contrariamente, para
Miguel Ángel el cuerpo es de dominio imperfecto: no se es señor del propio cuerpo, se dispone de él sólo de manera relativa. Así también el cadáver. Aunque con distinta intención, tanto para la medicina como para Miguel Ángel, el cuerpo y el cadáver son materia sagrada, inviolable.

\section{Referencias}

1. Quigle C. The corpse: a history. New York: McFarland \& Company, 2005.

2. Laín Entralgo P. Historia de la medicina. Barcelona: Salvat, 1981.

3. Laín Entralgo P. El cuerpo humano. Oriente y Grecia antigua. Madrid: Espasa-Calpe, 1987.

4. Laín Entralgo P. El cuerpo humano. Teoría actual. Madrid: Espasa-Calpe, 1989.

5. President's Commission for the Study of Ethical Problems in Medicine and Biomedical and Behavioral Research. Defining death: A report on the medical, legal and ethical issues in the determination of death. Washington: U.S. Government Printing Office, 1984.

6. Sudnow D. The social organization of dying. New York: Prentice-Hall, 1967.

7. Escalante JL. La definición de muerte. En: Gafo J, editor. Trasplante de órganos: problemas técnicos, éticos y legales. Madrid: Universidad Pontificia Comillas, 1996. p. 55-59.

8. de Tolnay M. Michelangelo: sculptor, painter, architect. Princeton: Preinton University Press, 1975.

9. de Tolnay M. The complete work of Michelangelo. New York: Barnes and Noble, 1997.

10. Figueroa G. El cuerpo humano en el "Moisés” de Miguel Ángel. Rev Med Chile 2013; 141: 1321-6.

11. Perrig A. Michelangelo Bounarroti letzte Pietà-Idee: ein Beitrag zur Erforschung seines Alterwerke. Berna: Peter Lang, 1960.

12. Frank G. The enigma of Michelangelo's Pietà Rondanini: a study of mother-loss in childhood. American Imago 1966; 23: 287-315.

13. Oremland J. Michelangelo's Pietàs. Psychoanal Study of the Child 1978: 33: 563-91.

14. Heidegger M. Sein und Zeit. 10. Aufl. Tübingen: Niemeyer; 1963.

15. Biemel W. Heideggers Begriff des Daseins. Studia Catholica 1949; 24: 113-29.

16. Demske JM Sein, Mensch und Tod. Das Todesproblem bei Martin Heidegger. Freiburg/München, 1963.

17. Ricoeur P. La memoire, l'histoire, l oubli. Paris: Seuil, 2000.

18. Ortega y Gasset J. La razón histórica. Obras Completas XII. Madrid: Alianza, 1940. p. 147-237. 
19. Figueroa G. Ortega y Gasset y la psiquiatría biológica: "Si queremos que todo siga como está, es necesario que todo cambie”. Rev Chil Neuro-Psiquiat 2006; 44: 13446.

20. Figueroa G. La muerte en la historia y en la medicina (I parte). Bol Soc Chil Anat Patol 2002; 17: 18-26.

21. Figueroa G. La muerte en la historia y en la medicina (II parte). Bol Soc Chil Anat Patol. 2002; 17: 14-20.

22. Ariès P. Geschichte des Todes. 2. Auflage. München: Deutscher Taschenbuch Verlag, 1985.

23. Ariès P. Essais sur l'histoire de la mort en Occident du moyen age à nos jours. Paris: Seuil, 1977.

24. Aristóteles. Ética a Nicómaco. Madrid: Centro de Estudios Constitucionales, 1985.

25. Gracia D. Ética de los confines de la vida. Santa Fe de Bogotá: El Búho, 1998.

26. Aristóteles. Metafísica. 2 volúmenes. Madrid: Gredos, 1970.

27. Pernick MS. Brain death in a cultural context: the reconstruction of death, 1967-1981. En: Younger SJ, Arnold RM, Schapiro R, editors. The definition of death: contemporary controversies. Baltimore: The John Hopkins University Press, 1999. p. 99-112.

28. Gracia D. Como arqueros al blanco. Estudios de bioética. Madrid: Triacastela, 2004.

29. Beecher HK. Ethical problems created by the hopelessly unconscious patients. New Engl J Medicine 1968; 278 :
427-31.

30. Kant I. Kritik der praktischen Vernunft. Band 6. Darmstadt: Wissenschaftliche Buchgessellschaft, 1968. p. 107-300.

31. Heidegger M. Der Ursprung des Kunstwerkes. Gesamtausgabe 5. Frankfurt: Klostermann, 1984. p. 7-68.

32. Heidegger M. Wissenschaft und Besinnung. En: Vortäge und Aufsätze. 5. Aufl. Pfullingen: Neske, 1967. p. 41-66.

33. Figueroa G. La bioética actual: las interrogantes de Heidegger. Rev Med Chile 2011; 139: 1377-82.

34. Zöllner F, Thoenes C. Michelangelo: complete works. Stuttgart: Taschen, 2014.

35. Zaner RM. The problema of embodiment. Some contributions to a phenomenology of the body. 2nd edition. The Hague: Martinus Nijhoff, 1971.

36. Baudelaire C. Écrits sur l'art. Paris: Le Libre du Poche, 1992.

37. Condivi, A. The life of Michelangelo. Baton Rouge: Louisiana State University Press, 1975.

38. Platón. Crátilo. En: Apología de Sócrates, Menón, Crátilo. Madrid: Alianza, 2004. págs. 171-217.

39. Ortega y Gasset J. Vitalidad, alma, espíritu. Obras Completas. Tomo II. Madrid: Revista de Occidente, 1924. p. 451-80.

40. Laín Entralgo P. Miguel Ángel y el cuerpo humano. En: Teatro del mundo. Madrid: Espasa-Calpe, 1986. p. 86104. 